\title{
||||||||||||||||||||||||||||||||||||||||||||||||||||||||||||||||||.
}

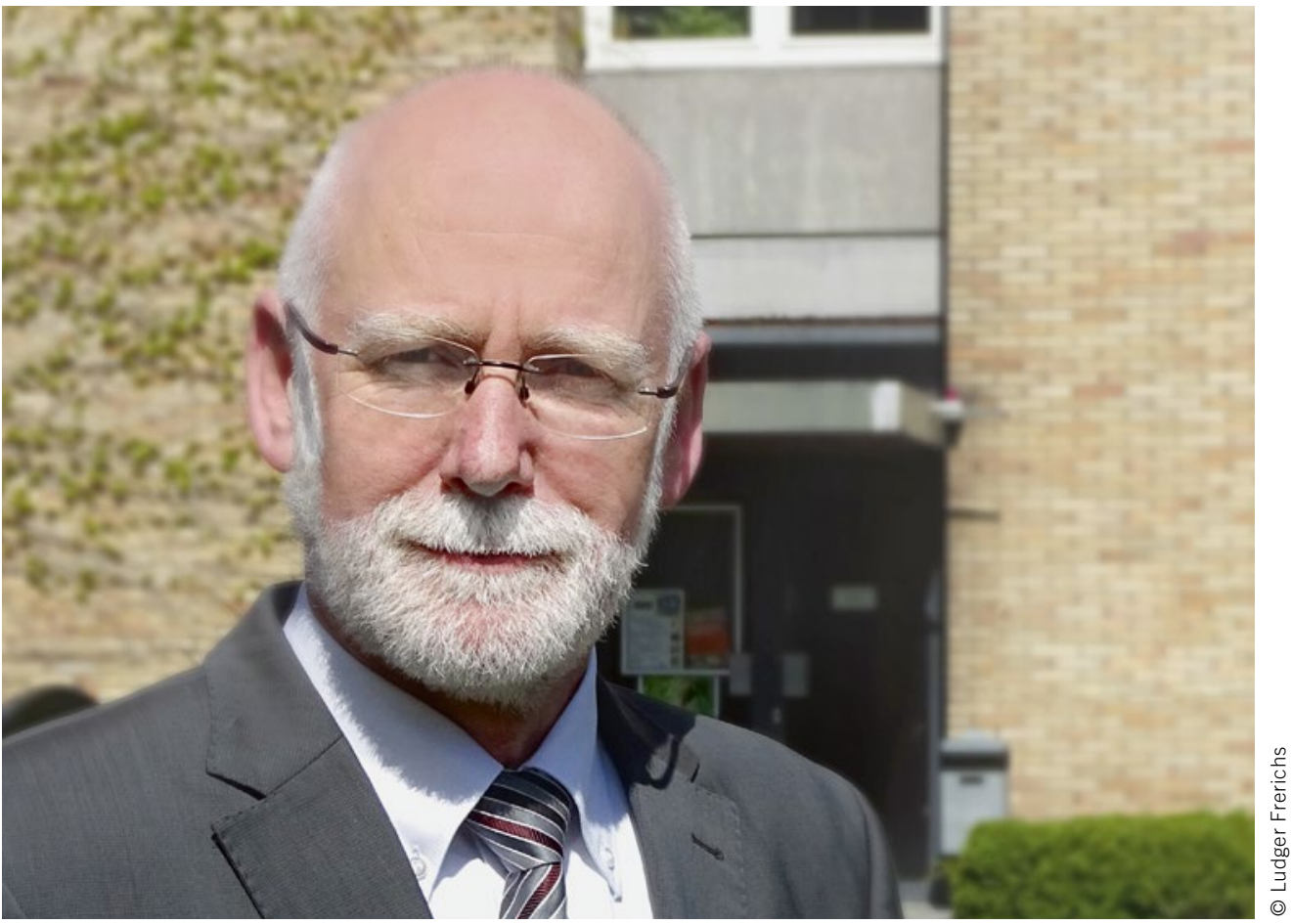

Prof. Dr. Ludger Frerichs

Leiter des Instituts für mobile Maschinen und Nutzfahrzeuge der Technischen Universität Braunschweig

\section{Die Wende vorbereiten}

Das Kürzel 4.0 gilt aktuell als Synonym für eine Charakterisierung zukunftsfähiger technischer Systeme. So werden auch die neuen, im Besonderen von mobilen Offroad-Maschinen geprägten Systeme mit Baustelle 4.0 oder Landwirtschaft 4.0 umschrieben. Vom Ursprung her ist damit nicht weniger gemeint als eine weitere technische Revolution und der Beginn eines neuen technischen Zeitalters. Mir erscheint das auch als durchaus zutreffend, denn wir stecken bereits mitten in diesen breit angelegten Umwälzungen. Die Entwicklungen gehen über die Bedeutung von Industrie 4.0 und die Schaffung von ganzheitlich funktionierenden Systemen, den Cyber Physical Systems, hinaus. Mindestens genauso umwälzend werden die Menschen hochautomatisierte oder autonome Maschinensysteme auf der Baustelle und auf dem Acker empfinden. Gehen Sie einmal mit dem Bild von Milchkanne und Melkschemel vor Augen in einen modernen Kuhstall und lassen sie dann die Arbeit des Melkroboters auf sich wirken. In dieser vor Jahren nicht vorstellbaren Art wird sich auch der technische Wandel auf dem Acker und auf der Baustelle vollziehen.

Es muss sich jedoch noch eine weitere Wende vollziehen, eine Energiewende. Hersteller und Forschungsstellen arbeiten in vielfältiger Form an der Steigerung der Energieeffizienz. In einer aktuellen Initiative der Land- und Baumaschinenhersteller, den Kraftstoffverbrauch und die $\mathrm{CO}_{2}$-Emissionen noch weiter drastisch zu verringern, werden in der nächsten Zeit branchen- weit mit dezidierten Forschungs- und Entwicklungsarbeiten die Bemühungen noch einmal verbindlich verstärkt.

Darüber hinaus werden wir in der Energiefrage an sogenannten Sprungentwicklungen arbeiten müssen. Wer mag, kann dafür einen weiteren Modebegriff verwenden - die disruptive Entwicklung. Für die Fahrzeuge und mobilen Maschinen im Offroad-Einsatz mit ihren hohen Leistungen und langen Einsatzzeiten sind wir heute auf Verbrennungsmotoren sowie Kraftstoffe mit hoher Energie- und Leistungsdichte angewiesen. Daran wird sich über Optimierungen hinaus kurzfristig auch nichts ändern. Aber genau hier setzt die Disruption, also die laut Duden „störende“ und das Herkömmliche „zerreißende“ Entwicklung an. Wir sind gefordert, die Kraftstofffrage und die Antriebstechnologien einschließlich der Infrastrukturen grundsätzlich neu zu denken. Ansätze dafür gibt es bereits, und diese auch soweit, dass sie in einigen Branchen standardmäßig eingesetzt werden: In Baumaschinen für den Untertageeinsatz findet sich beispielsweise die elektrische Direktversorgung; batterieelektrische Stapler mit Lade- und Batteriewechselkonzepten kennen wir seit Jahrzehnten und dort finden sich auch Brennstoffzellenantriebe. Und das sind nur die bekannten Ansätze. Diese und ganz neue Lösungen systemisch für die 4.0-Landwirtschaft und -Baustelle darzustellen, das sind gemeinsam mit den genannten CPS- und Automatisierungsthemen die großen Forschungs- und Entwicklungsaufgaben der Zukunft. 